Original Research

\title{
Structural Equation Modeling on Effects of Community Empowerment and Supplementary Feeding on Health Status and Nutritional Status of Pregnant Women
}

\section{Lantin Sulistyorini}

Faculty of Nursing, Universitas Jember, East Java, Indonesia

\section{ABSTRACT}

Introduction: rates of health problems related to a chronic lack of energy in pregnant women in Indonesia remain prevalence. This study aimed to develop community empowerment and supplementary feeding on health status and nutritional status among pregnant women.

Methods: the sample included 189 pregnant women living in the six villages in the Jember District. The research used a cluster random sampling technique. The variables included community empowerment, supplementary feeding, health status, and nutritional status of pregnant women. Data analysis was performed using structural equation modeling (SEM) with parameter data estimation using software (Analysis of Moment Structures (AMOS) version 21).

Results: estimations of the direct effects were as follows: community empowerment on health status (0.224), supplementary feeding on health status (0.169), health status on nutritional status of pregnant women (0.001), community empowerment on nutritional status of pregnant women (2.857), supplementary feeding on nutritional status of pregnant women (-0.537), community empowerment on nutritional status of pregnant women through health status (0.000), supplementary feeding on nutritional status of pregnant women through health status (0.000), community empowerment on health status (0.224), supplementary feeding on health status (0.169).

Conclusion: community empowerment remains an important key in improving the engagement of women in maternal health issues. Combined intervention with supplementary feeding based on locality may improve the health outcomes.

\section{ARTICLE HISTORY}

Received: August 18, 2018

Accepted: Sept 14, 2018

\section{KEYWORDS}

community empowerment; health status; nutritional status, supplementary feeding.

\section{CONTACT}

Lantin Sulistyorini $\triangle$ lantin_s.psik@unej.ac.id $\fallingdotseq$ Faculty of Nursing, Universitas Jember, East Java, Indonesia

Cite this as: Sulistyorini, L. (2018). Structural Equation Modeling on Effects of Community Empowerment and Supplementary Feeding on Health Status and Nutritional Status of Pregnant Women. Jurnal Ners, 13(2), 128137. doi:http://dx.doi.org/10.20473/jn.v13i2.8995

\section{INTRODUCTION}

In Indonesia, data from October 2013 show the upper arm circumference threshold for chronic lack of energy risk is $23.5 \mathrm{~cm}$ (Ministry of Health, 2010). This illustrates that mothers with a chronic lack of energy risk will give birth to babies with low birth weights. When a baby is born with low birth weight, it is at risk of death, lack of nutrition, growth disorders, and developmental disorders. Efforts to prevent the risk of chronic lack of energy in pregnant women before pregnancy include increasing the nutritional intake of women of childbearing age to ensure the size of the upper arm circumference in women of childbearing age is at least $23.5 \mathrm{~cm}$ (Ministry of Health, 2009). If the circumference of the mother's upper arm before pregnancy is below this number, then it is better to delay the pregnancy in advance so as not to risk giving birth to a baby with low birth weight. However, the Ministry of Health, Republic of Indonesia (2009) showed that pregnant women with a chronic lack of energy and an upper arm circumference less than $23 \mathrm{~cm}$ are twice as likely to give birth to low-birth-weight infants compared with mothers who have an upper arm circumference of more than $23 \mathrm{~cm}$. Other health problems among pregnant women are related to low economic levels, low education, unhealthy environment, irregular eating patterns, and poor health conditions (Ministry of Health, 2010). Rates of health problems related to a chronic lack of energy in pregnant women in some villages in the Jelbuk Sub-district of Indonesia's Jember Regency are high (Department of Religious of Jember, 2011). The problem of a chronic lack of energy in the Jelbuk Sub-district of the Jember Regency remains common. 
In 2015 , there were reported to be 48 pregnant women with a chronic lack of energy in six villages: Jelbuk, Panduman, Sukowiryo, Sucopangepok, Sukojember, and Sugerkidul. Data from the public health center of Jelbuk (October 2015) indicated there were 40 pregnant women with a chronic lack of energy that had been handled. Of the 40 pregnant women with a chronic lack of energy, there were four cases of infants with low birth weight (Department of Religious of Jember, 2011).

One of the principal factors that influence the health status of pregnant women is nutrition. Risk factors that affect the nutritional status of pregnant women include low economic levels, low education, unhealthy environment, irregular eating patterns, and poor health conditions. The nutritional status of pregnant women affects the growth and development of the fetus (Bobak, 2004). Assessing the nutritional status of pregnant women includes monitoring weight gain during pregnancy, measuring the upper arm circumference, and measuring hemoglobin levels. Weight gain during pregnancy is approximately 10-12 kg (trimester 1: less than $1 \mathrm{~kg}$; trimester 2: about $3 \mathrm{~kg}$; trimester 3 : about $6 \mathrm{~kg}$ ). Weight gain each trimester is used to monitor fetal growth (Ministry of Health, 2010).

One solution to the problem of a chronic lack of energy in pregnant women is empowering the community to provide additional food to the local community health service program. Public health service programs are expected by the world health organization to reduce maternal and infant mortality and low-birth-weight cases. These can be implemented by organizing, mobilizing, and empowering the community by involving community leaders, religious leaders, and health cadres directly in families who have pregnant women. They aim to keep pregnant women well and ensure safe and healthy childbirth. This study aimed to develop community empowerment and supplementary feeding model on health status and nutritional status among pregnant women.

\section{MATERIALS AND METHODS}

This study was conducted from July 2017 to August 2017 at Jember Regency, Indonesia. This study adopted a cross-sectional approach by recruiting pregnant women living in those regency. Inclusion criteria for research sites included: 1) Jelbuk, Panduman, Sukowiryo, Sucopangepok, Sukojember, and Sugerkidul in Jelbuk, Jember District; 2) pregnant women in these 6 villages who have a very young age of marriage and pregnancy; 3) pregnant women in the 6 villages who are lazy to come to the posyandu; 4) pregnant women in these 6 villages whose nutritional needs are not met due to low economic income so that food nutrition patterns are not met properly; 5) pregnant women in these 6 villages who have low family and community knowledge about the condition or initial symptoms of lack of calorie energy so that they are not given early treatment and become more severe with the occurrence of low birth weight or maternal and infant mortality; 6) Posyandu in these 6 villages that are still less than optimal is related to cadre training on protein lack of energy; 7) the coverage of the target on the lack of protein energy in the 6 villages that still have no screening plans for pregnant women by posyandu and dukun cadres; 8) the use of plantation resources and local agriculture in these 6 villages is less than optimal as an effort to improve family nutrition in overcoming protein lack of energy.

The sampling technique was cluster random sampling, because the population was separated according to certain clusters (i.e., villages). The sample included pregnant women $(n=189)$ in the villages of Sukowiryo, Jelbuk, Sugerkidul, Sukojember, Sucopangepok, and Panduman, Jember Regency. The research instruments used were a Likert-scale questionnaire to find out the level of knowledge (low, medium, and high), attitude (i.e., behavior attitude), and motivation (i.e., level of enthusiasm). Weight scales were used to find out the increase or decrease in weight, and a meter stick was used to find out the height increase. Health status was assessed using a questionnaire. The level of pregnancy knowledge and level of nutrition knowledge were assessed. An upper arm circumference meter was used to find out the increase or decrease in the upper arm circumference, and a gestational age card was used to control pregnancy health. A Tetanus Toxoid (TT) immunization card was used to find out the completeness of TT immunization, and a Ferrous (Fe) tablet was used to find out the supplementary supplement fulfillment. The height of the uterine fundus was measured to determine the growth and development of the uterus, and a sphygmomanometer was used to detect high or low blood pressure.

Data collection techniques included having participants fill out the questionnaire on knowledge level, attitude, motivation, pregnancy knowledge level, and nutritional knowledge level; having participants fill out the TT immunization data form; Ferrous tablets; and measuring body weight, height, circumference of the upper arm, height of the uterine fundus, and blood pressure.

Data analysis was performed using structural equation modeling (SEM) with parameter data estimation using software (Analysis of Moment Structures (AMOS) (Byrne, 2013). SEM functioned to assess the latent variables at the observation level (Bagossi \& Yi, 2012). The SEM test simultaneously tested the model (Kline, 2015), which estimated the effect of community empowerment and supplementary feeding on the health status and nutritional status of pregnant women. The study analyzed the estimated direct effects, estimated indirect effects, and estimated total effects between and among variables. The estimated direct effects of 
the following variables were examined: 1) community empowerment (X1) on health status (Y1); 2) supplementary feeding (X2) on health status (Y1); 3) health status (Y1) on nutritional status of pregnant women (Y2); 4) community empowerment (X1) on nutritional status of pregnant women (Y2); 5) supplementary feeding (X2) on nutritional status of pregnant women (Y2). The estimated indirect effects of the following variables were examined: 1) community empowerment (X1) on nutritional status of pregnant women (Y2) through health status (Y1); 2) supplementary feeding (X2) on nutritional status of pregnant women (Y2) through health status (Y1). The estimated total effects of the following variables were examined: 1) the sum of all direct effects of community empowerment (X1) on health status (Y1) and indirect effects of community empowerment (X1) on health status (Y1); 2) the sum of all direct effects of supplementary feeding (X2) on health status (Y1) and indirect effects of supplementary feeding (X2) on health status (Y1).

\section{RESULTS}

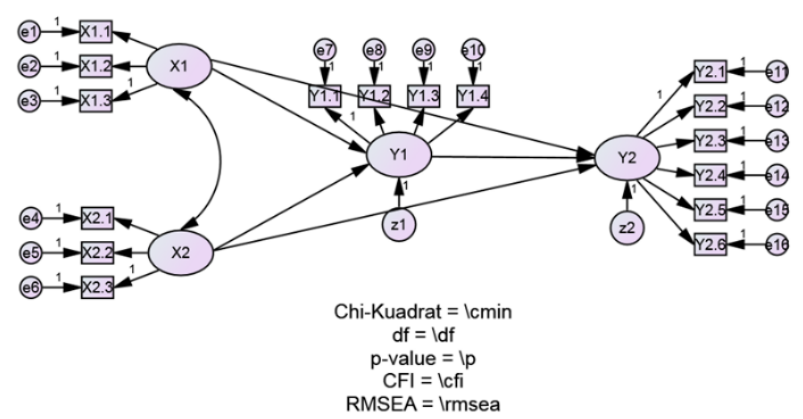

Figure 1. Hypothesis Model on Effect of Community Empowerment and Supplementary Feeding on Health Status and Nutritional Status of Pregnant Women.

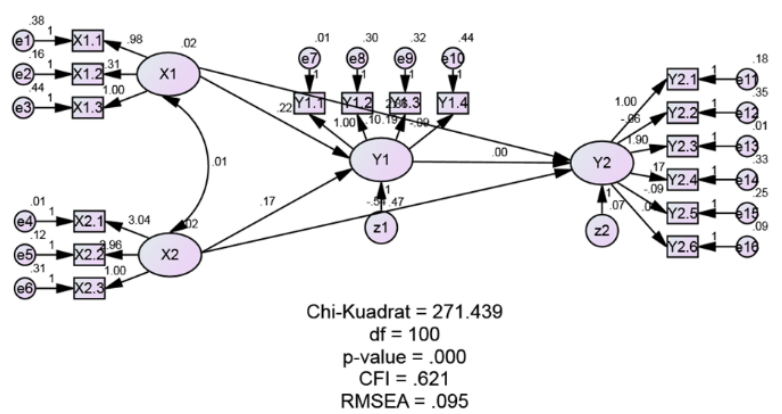

Figure 2. Structural Equation Model: Effect of Community Empowerment and Supplementary Feeding on Health Status and Nutritional Status of Pregnant Women.

Variables of community empowerment (X1) included knowledge level (X1.1), attitude (X1.2), and motivation (X1.3). Supplementary feeding variables (X2) included body weight before pregnancy (X2.1), weight after pregnancy (X2.2), and height (X2.3). The health status variables (Y1) included pre-pregnancy knowledge level (Y1.1), post-pregnancy knowledge level (Y1.2), pre-pregnancy nutritional status (Y1.3), and post-pregnancy nutritional status (Y1.4). Maternal nutritional status variables (Y2) included upper arm circumference (Y2.1), gestational age 130 | pISSN: 1858-3598 • eISSN: 2502-5791
(Y2.2), TT immunization (Y2.3), Fe tablet (Y2.4), high uterine fundus (Y2.5), and blood pressure (Y2.6). All of the variables and indicators are shown in Figure 1.

In Figure 2 it is found that there is a direct influence of community empowerment (X1) on health status (Y1) of 0.224. There is a direct effect of supplementary feeding (X2) on health status (Y1) of 0.169 . There is a direct effect of health status (Y1) on the nutritional status of pregnant women (Y2) of 0.001 . There is a direct influence of community empowerment (X1) on the nutritional status of pregnant women (Y2) of 2,857. There is a direct effect of supplementary feeding (X2) on the nutritional status of pregnant women (Y2) of -0.537.

\section{Estimation of Direct Effects}

Based on Table 1, the value of 0.224 is the estimation of the direct effect (unstandardized structural loading) of community empowerment (X1) on health status (Y1). This value means that if the level of community empowerment (X1) increases 1 unit, then the health status level (Y1) will increase by 0.224 units.

The value of 0.169 is the estimation of the direct effect (unstandardized structural loading) of supplementary feeding (X2) on health status (Y1). This value means if the level of supplementary feeding (X2) increases 1 unit, then the health status level (Y1) will increase by 0.169 units.

The value of 0.001 is the estimation of the direct effect (unstandardized structural loading) of health status (Y1) on the nutritional status of pregnant women (Y2). This value means that if the health status level (Y1) increases 1 unit, then the nutritional status of pregnant women (Y2) will increase by 0.001 units.

The value of 2.857 is the estimation of the direct effect (unstandardized structural loading) of community empowerment (X1) on the nutritional status of pregnant women (Y2). This value means that if the level of community empowerment (X1) increases 1 unit, then the nutritional status of pregnant women (Y2) will increase by 2.857 units.

The value of -0.537 is the estimation of the direct effect (unstandardized structural loading) of supplementary feeding (X2) on the nutritional status of pregnant women (Y2). This value means that if the supplementary feeding rate (X2) increases 1 unit, then the nutritional status of pregnant women (Y2) will increase by -0.537 units.

\section{Estimation of Indirect Effects}

Based on Table 1, the estimation of the individual indirect effect of community empowerment (X1) on the nutritional status of pregnant women (Y2) through health status (Y1) is $0.224 * 0.001=0.000$. This means the level of nutritional status of pregnant women (Y2) will increase by 0.000 units per 1-unit increase of community empowerment (X1) after mediation by health status (Y1). Therefore, the total coefficient of the indirect effect of community 
Table 1. The direct, indirect and total effects of Community Empowerment and Supplementary Feeding on Health Status and Nutritional Status of Pregnant Women

\begin{tabular}{|c|c|c|c|c|}
\hline Variables & & Direct & Indirect & Total \\
\hline $\begin{array}{l}\text { Y1 < - - } \\
\text { X1 }\end{array}$ & Estimate & 0.224 & & \\
\hline \multicolumn{5}{|c|}{ p-value 0.000} \\
\hline $\begin{array}{l}\mathrm{Y} 1<\cdots \\
\mathrm{X} 2\end{array}$ & Estimate & 0.169 & & \\
\hline & p-va & ue 0.00 & & \\
\hline $\begin{array}{l}Y 2<\cdots \\
Y 1\end{array}$ & Estimate & 0.001 & & \\
\hline & p-va & ue 0.00 & & \\
\hline $\begin{array}{l}Y 2<\cdots \\
X 1\end{array}$ & Estimate & 2.857 & & \\
\hline & p-va & ue 0.00 & & \\
\hline $\begin{array}{l}\mathrm{Y} 2<\cdots \\
\mathrm{X} 2\end{array}$ & Estimate & -0.537 & & \\
\hline & p-va & ue 0.00 & & \\
\hline $\begin{array}{l}\mathrm{X} 1 \text { - - -> } \\
\mathrm{Y} 1\end{array}$ & Estimate & & 0.224 & \\
\hline & p-va & ue 0.00 & & \\
\hline Y1 - - -> & Estimate & & 0.001 & \\
\hline$x 2 \rightarrow$ & p-value & & 0.000 & \\
\hline $\begin{array}{l}\mathrm{X} 2-\cdots> \\
\mathrm{Y} 1\end{array}$ & Estimate & & 0.169 & \\
\hline $\begin{array}{l}\text { Y1 - - -> } \\
\text { Y2 }\end{array}$ & $\begin{array}{l}\text { p-value } \\
\text { Estimate }\end{array}$ & & $\begin{array}{l}\mathbf{0 . 0 0 0} \\
0.001\end{array}$ & \\
\hline & p-value & & 0.000 & \\
\hline $\begin{array}{l}\mathrm{Y} 1<\cdots \\
\mathrm{X} 1\end{array}$ & Estimate & & & 0.224 \\
\hline $\begin{array}{l}\mathrm{Y} 1<-\cdots \\
\mathrm{X} 2\end{array}$ & $\begin{array}{l}\text { p-value } \\
\text { Estimate }\end{array}$ & & & $\begin{array}{l}\mathbf{0 . 0 0 0} \\
0.169\end{array}$ \\
\hline $\begin{array}{l}\mathrm{Y} 2<\ldots \\
\mathrm{Y} 1\end{array}$ & $\begin{array}{l}\text { p-value } \\
\text { Estimate }\end{array}$ & & & $\begin{array}{l}\mathbf{0 . 0 0 0} \\
0.001\end{array}$ \\
\hline $\begin{array}{l}\mathrm{Y} 2<-- \\
\mathrm{X} 1\end{array}$ & $\begin{array}{l}\text { p-value } \\
\text { Estimate }\end{array}$ & & & $\begin{array}{l}\mathbf{0 . 0 0 0} \\
2.857\end{array}$ \\
\hline $\begin{array}{l}\mathrm{Y} 2<\cdots \\
\mathrm{X} 2\end{array}$ & $\begin{array}{l}\text { p-value } \\
\text { Estimate } \\
\text { p-value }\end{array}$ & & & $\begin{array}{l}\mathbf{0 . 0 0 0} \\
- \\
0.537 \\
\mathbf{0 . 0 0 0}\end{array}$ \\
\hline
\end{tabular}

empowerment (X1) on the nutritional status of pregnant women (Y2) is equal to 0.000 .

The estimation of the individual indirect effect of supplementary feeding (X2) on the nutritional status of pregnant women (Y2) through health status (Y1) is $0.169 * 0.001=0.000$. This means the level of nutritional status of pregnant women (Y2) will increase by 0.000 units per 1-unit increase in supplementary feeding (X2) after mediation by health status (Y1). Therefore, the total coefficient of the indirect effect of supplementary feeding (X2) on maternal nutritional status (Y2) is 0.000 .

\section{Estimation of Total Effects}

The estimation of total effects is as follows: $\mathrm{x} 1$-- > $\mathrm{y} 1, \mathrm{x} 2-->\mathrm{y} 1$. In Table 1, it was found that the estimated direct effect of community empowerment (X1) on health status (Y1) $=0.224$. In Table 1 , it was found that the estimated total indirect effect of community empowerment (X1) on health status (Y1) $=0.000$. Thus, the estimated total effect of community empowerment (X1) on health status (Y1) $=0.224+0.000=0.224$. These results can be interpreted as follows: the health status (Y1) will rise by 0.224 units for each 1-unit increase in community empowerment (X1) after passing all the paths between the two variables. In Table 1, it was found that the estimated direct effect of supplementary feeding (X2) on health status (Y1) = 0.169. In Table 1, it was found that the estimated total indirect effect of supplementary feeding (X2) on health status $(\mathrm{Y} 1)=0.000$. Thus, the estimated total effect of supplementary feeding (X2) on health status (Y1) $=0.169+0.000=0.169$. This result can be interpreted as follows: the health status (Y1) will rise by 0.169 units for each 1-unit supplementary feeding increase (X2) after passing all the paths between the two variables.

\section{DISCUSSION}

\section{Direct Effect Estimation \\ Effect of Community Empowerment on Health Status}

The value of 0.224 is the estimation of the direct effect (unstandardized structural loading) of community empowerment (X1) on health status (Y1). This value means that if the level of community empowerment (X1) rises 1 unit, then the health status level (Y1) will rise by 0.224 units.

Variables of community empowerment include level of knowledge, attitude, and motivation. The concept varies according to cultural influences (Olmedo-Alguacil et al., 2015). The level of knowledge of pregnant women about quality of life is associated with different health statuses for individuals with different cultural or ethnic backgrounds (Kagawa-Singer et al., 2010). Pregnancy is a unique time in a mother's life. Striking physiological, metabolic, social, and psychological changes can modify the ability of pregnant women to perform traditional roles and improve their health status associated with maternal life (Montoya et al., 2010). The physiological effects of pregnancy can result in sleep disturbances. Thus, fatigue the physical and mental state associated with maternal knowledge levels about the quality of life during pregnancy and in non-obese pregnant women (Tsai et al., 2016). This suggests that the maternal knowledge level of quality of life is related to health status. Similarly, a Mexican study reported that physical and mental component scores were significantly lower in obese pregnant women than in non-obese pregnant women (Amador-Licona \& 
Guizar-Mendoza, 2012; Amador et al., 2008). The level of knowledge of pregnant women about their quality of health is associated with women's lives in terms of their self-confidence and breastfeeding motivation (Zubaran \& Foresti, 2011). Increasing pregnant women's level of knowledge about quality of life can improve their health status (Ministry of Health, Republic of Indonesia, 2004).

\section{Effect of Supplementary Feeding on Health Status}

The value of 0.167 is the estimated standardized non-standard loading effect of supplemental feeding (X2) on health status (Y1). This value means if the level of supplementary feeding (X2) goes up 1 unit, then the health status level (Y1) will rise by 0.169 units.

Supplementary feeding variables include body weight and height. Pregnant women of normal weight with higher education levels have higher levels of nutritional knowledge along with positive breastfeeding preparation attitudes (Lau et al., 2016). The results of a study in Singapore indicated that the prevalence of overweight or obesity prepregnancy is $25 \%$ and that pre-pregnancy obesity can affect the health status of pregnant women, leading to conditions such as preeclampsia. This figure is lower than the proportion of overweight or obese pregnant women aged 18 to 69 years (Ministry of Health, 2010), which was 45\% worldwide in 2014 (World Health Organization, 2016). The differences are due to different age and race composition factors. The results of research in Singapore show that overweight and obesity rates increased by about $1 \%$ per year, especially in Malay and Indian races (Ministry of Health, 2010). It is related to the comfort factor of eating outdoors. As many as $60 \%$ of Singaporeans regularly eat in public places, such as hawker centers, food courts, and coffee shops, and Singaporeans consume excessive calories and fat (Health Promotion Board, 2010). The results suggest that Malay and Indian diets contain more saturated fats and highly nutritious foods (Neelakantan et al., 2016). Other research finds that women alter their physical activity and dietary patterns during pregnancy (Chen et al., 2013; Padmapriya et al., 2015). Pregnant women in Singapore refuse physical activity and increase sitting time, television viewing time (Padmapriya et al., 2015), and consumption of milk, fruit, vegetables, rice, noodles, and bread (Chen et al., 2013). Pregnant women of the Malay and Indian races more often increase sitting time during pregnancy compared to the Chinese race in Singapore. Lifestyle changes, especially pregnant women's knowledge of nutrition, can increase the number of overweight or obese pregnant women in Singapore (Padmapriya et al., 2015).

\section{Effect of Health Status on Nutritional Status of Pregnant Women}

The value of 0.001 is an estimate of the (unstandardized structural loading) effect of health status (Y1) on the nutritional status of pregnant women (Y2). This value means that if the health status level (Y1) rises 1 unit, then the nutritional status of pregnant women (Y2) will increase by 0.001 units.

Variables of health status include the level of knowledge of pregnancy and the level of nutritional knowledge. A study of the effects of maternal knowledge levels of pregnancy on body weight during pregnancy found that the prevalence of overweight or obesity around the world is $39 \%$ and $13 \%$, respectively, in women of reproductive age (World Health Organization, 2016). The results showed that knowledge of breastfeeding preparation is influenced by maternal obesity (Turcksin et al., 2014). This is because mothers' overweight or obesity significantly affects the initiation and duration of breastfeeding but only slightly affects their attitude in preparation for breastfeeding (Amir \& Donath, 2007; Turcksin et al., 2014). The results of the study showed that pregnant women are less likely to be obese during breastfeeding preparation than non-obese women (Guelinckx et al., 2012). Other results found that obese pregnant women were no different from non-obese pregnant women in motivation for breastfeeding preparation (Hauff et al., 2014).

\section{Effect of Community Empowerment on Nutritional Status of Pregnant Women}

The value of 2.857 is the estimation of the nonstandardized impact of loading (structural loading) from community empowerment (X1) on the nutritional status of pregnant women (Y2). This value means that if the level of community empowerment (X1) rises 1 unit, then the nutritional status of pregnant women (Y2) will increase by 2.857 units.

Variables of community empowerment include pregnant women's level of knowledge, attitude, and motivation. The attitude of pregnant women is very important in optimizing fetal health and well-being, as it is beneficial in the short- and long-term to mother, child, family, and society (Victora et al., 2016; Lau et al., 2016). This is one of the factors associated with the behavior of breastfeeding (Linares et al., 2015). The attitude of pregnant women is a predictive factor of exclusive breastfeeding initiation (Cox et al., 2015; Linares et al., 2015; Wang et al., 2014). It is also present in the antenatal period and is influenced by multidimensional factors (Roll \& Cheater, 2016). Factors affecting maternal attitude to breastfeeding include maternal characteristics, including age (Nouer et al., 2015), ethnicity (Linares et al., 2015), education level, occupational status (Ishak et al. 2014), household income (Persad \& Mensinger, 2008), parity (Buckles \& Kolka, 2014), pregnancy intentions (Kost \& Lindberg, 2015), caregivers (Fok 
et al., 2016), and previous exclusive breastfeeding experience (Mitra et al., 2004). Community empowerment, such as a good level of knowledge, can influence maternal attitudes on improving health status.

\section{Effect of Supplementary Feeding on Pregnant Women's Nutritional Status}

The value of -0.537 is the estimated standardized non-standard loading effect of supplementary feeding (X2) on the nutritional status of pregnant women (Y2). This value means that if the supplementary feeding rate (X2) rises 1 unit, then the nutritional status of pregnant women (Y2) will rise by -0.537 units.

Supplementary feeding variables include the weight and height of pregnant women. According to the nutritional adequacy rate of 2004, a pregnant mother is encouraged to consume the following additional amounts of energy and protein: (1) first trimester: 100 calories and 17 grams of protein; (2) second trimester: 300 calories and 17 grams of protein; (3) third trimester: 300 calories and 17 grams of protein. In this way, expectations can be met in three consecutive trimesters. The need for vitamins and minerals in all three trimesters also increases. Pregnant women need additional vitamin A (300 RE), thiamin (0.3 $\mathrm{mg})$, riboflavin $(0.3 \mathrm{mg})$, niacin $(0.3 \mathrm{mg})$, folic acid $(200 \mathrm{mcg})$, pyridoxine $(0.4$ $\mathrm{mg})$, vitamin B (0.2 $\mathrm{mcg})$, vitamin C (10 mg), calcium (150 mg), magnesium (30 mg), iodine (50 mcg), selenium ( $5 \mathrm{mcg}$ ), manganese $(0.2 \mathrm{mg}$ ), and fluoride (0.2 mg). The additional iron requirement in pregnant women varies. In the first trimester, they do not require additional iron. However, in trimester 2 , they require as much as $9 \mathrm{mg}$, and in trimester 3 , they require as much as $13 \mathrm{mg}$. The additional need for zinc is as follows: trimester 1: $1.7 \mathrm{mg}$; trimester 2: $4.2 \mathrm{mg}$; trimester 3: $9 \mathrm{mg}$.

\section{Indirect Effect Estimation}

Effect of Community Empowerment on Nutritional Status of Pregnant Women through Health Status

The estimation of the individual indirect influence of community empowerment (X1) on the nutritional status of pregnant women (Y2) through health status (Y1) is $0.224 * 0.001=0.000$. This means that the level of nutritional status of pregnant women (Y2) will increase by 0.000 units per 1 -unit increase of community empowerment (X1) after mediation by health status (Y1). Therefore, the total coefficient of the indirect effect of community empowerment (X1) on the nutritional status of pregnant women (Y2) is equal to 0.000 .

During pregnancy, pregnant women should prepare to welcome the birth of a baby by increasing their knowledge about pregnancy and complete nutrition. A healthy mother will give birth to a healthy baby. Maternal nutrition during pregnancy is one of the determining factors that affect the baby's birth. During pregnancy, there is an increased need for nutrients, such as carbohydrates, proteins, vitamins, and minerals (Hasugian, 2012). Therefore, pregnant women with adequate knowledge can increase their nutritional intake as needed during pregnancy to improve health status.

\section{Effect of Supplementary Feeding on Nutritional Status of Pregnant Women through Health Status}

The estimation of the individual indirect effect of supplementary feeding (X2) on the nutritional status of pregnant women (Y2) through health status (Y1) is $0.169 * 0.001=0.000$. This means the level of nutritional status of pregnant women (Y2) will increase by 0.000 units per 1-unit supplementary feeding increase (X2) after mediation by health status (Y1). Therefore, the total coefficient of the indirect effect of supplementary feeding (X2) on maternal nutritional status (Y2) is 0.000 .

Fulfillment of nutritional needs is very important, especially related to changes in the mother's body and fetal development. During pregnancy in the mother, there are various physical and physiological changes. In a normal pregnancy, there is a change in maternal weight gain in accordance with fetal growth and development due to the addition of fat reserves, placental formation and development, increased body fluids, and breast enlargement.

Due to hormonal changes, pregnant women will experience psychological, social, and emotional changes. A fetus that grows optimally will be born alive with a weight of 2500-3500 grams. To achieve that goal, the mother's weight should rise during pregnancy by about 7-12 kg.

Nutritional requirements during pregnancy are higher compared to pre-pregnant conditions. As gestation progresses, mothers need a higher number of nutrients and additional foods. The aim of optimizing nutritional intake according to gestational age is to achieve a healthy pregnancy.

The quantity, quality, and timeliness of supplementary feeding in pregnant women are adjusted to the rate of fetal growth in each trimester. In the first trimester, there is an increase in the number of cells and the formation of organs. This process needs to be supported by the intake of nutrients, especially protein, folic acid, vitamin B12, zinc, and iodine. Although fetal growth is not rapid in the first trimester, all necessary nutrients must be sufficient in preparation for faster growth in the next trimester. In the second and third trimesters, the fetus grows rapidly to $90 \%$ of all growth processes during pregnancy. Nutrients needed are protein, iron, calcium, magnesium, vitamin B complex, and omega 3 and omega 6 fatty acids. Additional energy needs during pregnancy are different in each trimester. In the first trimester, the major nutrient additions are proteins, vitamins, and minerals necessary for the growth of the brain and nerve cells, which mostly takes place during the first trimester. In the second and third trimesters, average energy 
requirements increase by 350 to 500 calories per day. The energy and nutrient needs of pregnant women are very diverse, because it relates to the size of the body and lifestyle of each pregnant woman. Simply, nutritional adequacy during pregnancy can be monitored by weight gain appropriate to gestational age (Ministry of Health, 2009).

There is a relationship between community empowerment/providing additional food and health status. This is seen in pregnant women who consume nutritious foods derived from carbohydrates, proteins, vitamins, and minerals needed during pregnancy.

\section{Total Effect Estimation Effect of Community Empowerment on Health Status}

In Table 1, it was found that the estimated direct influence of community empowerment (X1) on health status $(\mathrm{Y} 1)=0.224$. It was also found that the total estimated indirect effect of community empowerment $(\mathrm{X} 1)$ on health status $(\mathrm{Y} 1)=0.000$. Thus, the estimated effect of total community empowerment (X1) on health status $(\mathrm{Y} 1)=0.224+$ $0.000=0.224$. These results can be interpreted as follows: the health status (Y1) will rise by 0.224 units for each 1-unit increase in community empowerment (X1) after passing all the paths between the two variables.

Variables of community empowerment include level of knowledge, attitude, and motivation. Negative perceptions of pregnant women on health status during pregnancy can lead to a decrease in the quality of life associated with health status (Kolu et al., 2014).

Respecting cultural differences in understanding quality of life as it relates to health status is important, because the dimensions and sources of social and religious support may differ between cultures (Kagawa-Singer et al., 2010). Research results in the United States show that Asians have a quality of life associated with better health status than Whites and other ethnic groups (Chowdhury et al. 2008; Zahran et al., 2005). Because Asians are very respectful of culture, a clean and healthy lifestyle has become one of their core beliefs.

Intellectual factors influence pregnant women making decisions on breastfeeding preparation (Chin et al., 2008), and pregnant women with high levels of education have more accurate breastfeeding knowledge than those with low levels of education (Zhou et al., 2010). This study is consistent with studies showing a positive relationship between knowledge of infant feeding and maternal decisionmaking on infant feeding (Radzyminski \& Callister, 2016; Roll \& Cheater, 2016). With a high level of knowledge and understanding, pregnant women can make informed decisions about the preparation for childbirth and breastfeeding.

\section{Effect of Supplementary Feeding on Health Status}

Table 1 shows that the estimated direct effect of supplementary feeding (X2) on health status (Y1) = 0.169. In Table 4, it was found that the total estimated indirect effect of supplementary feeding (X2) on health status (Y1) $=0.000$. Thus, the estimated total effect of supplementary feeding (X2) on health status $(\mathrm{Y} 1)=0.169+0.000=0.169$. This result can be interpreted as follows: the health status (Y1) will rise by 0.169 units for each 1-unit supplementary feeding increase (X2) after passing all the paths between the two variables.

Supplementary feeding variables include weight and height. The normal weight indicator shows the quality of life associated with a person's health status (Amador-Licona \& Guizar-Mendoza, 2012), especially the level of knowledge of pregnancy and nutrition. Pregnant women of normal weight with a high level of education have high levels of pregnancy knowledge and positive breastfeeding attitudes (Ishak et al., 2014; Nouer et al., 2015).

The results show that pregnant women who are in good health and leading happy lives have important health. Pregnant women today are more likely to consider breastfeeding an important part because of the many benefits of breastfeeding on health, and they are willing to participate in healthy breastfeeding behavior (Bakas et al., 2012). Pregnant women with a high quality of life associated with a better health status have positive attitudes toward breastfeeding. In contrast, the following characteristics of health status are associated with poor quality of life: poverty, fatigue, energy loss, depression, anxiety, labor difficulties (Ware et al., 1995). This illustrates that inadequate quality of life in pregnant women is associated with poor health status and low use of antenatal care services (Nisar et al., 2016). The results of previous studies suggest that pregnant women with few antenatal visits have a quality of life associated with low health status (de Oliveira et al., 2015). During an antenatal visit, attendance of healthcare support is crucial in the selection of baby food (Meedya et al., 2010). The results of research in Hong Kong show that pregnant women with low levels of antenatal knowledge have poor breastfeeding attitudes (Lau, 2010) because pregnant women decide to breastfeed during early pregnancy (Brand et al., 2011). This has an impact on pregnant women with a quality of life associated with poor health status and negative breastfeeding attitudes. A good level of understanding of supplementary feeding can create a positive attitude for pregnant women on health status.

\section{CONCLUSION}

Community empowerment and supplementary feeding aspect remain a critical part in improving general health and nutritional status of pregnant women. Health workers need to develop specific intervention in engaging community around maternal health areas. Supplementary feeding 
intervention also need to be done within villages by cooperating with local governments.

\section{REFERENCES}

Amador, N., Juarez, J.M., Guizar, J.M., \& Linares, B. (2008). Quality of life in obese pregnant women: a longitudinal study. Am. J. Obstet. Gynecol. 198 (2), 203. doi: http: //dx.doi.org/10.1016/j.ajog.20 07.08.037 e201-205.

Amador-Licona, N., \& Guizar-Mendoza, J.M. (2012). Daytime sleepiness and quality of life: are they related in obese pregnant women? Arch. Gynecol. Obstet. 285 (1), 105-109. doi: http: //dx.doi.org/10.10 07 / s0 0404 -011-1879-9.

Amir, L.H., \& Donath, S. (2007). A systematic review of maternal obesity and breastfeeding intention, initiation and duration. BMC Pregnancy Childbirth. 7, 9. doi: http: //dx.doi.org/10.1186/1471-2393-7-9.

Bagozzi, R.P., \& Yi, Y. (2012). Specifications, evaluation, and interpretation of structural equation models. J. Acad. Mark. Sci. 40, 8-34. doi: http://dx.doi.org/10.10 07/s11747-011-0278-x.

Bakas, T., McLennon, S.M., Carpenter, J.S., Buelow, J.M., Otte, J.L., Hanna, K.M., Ellett, M.L., Hadler, K.A., \& Welch, J.L. (2012). Systematic review of health-related quality of life models. Health Qual. Life Outcomes. 10, 134. doi: http://dx.doi.org/10.1186/1477-7525-10-134.

Bobak. (2004). Maternity Nursing Teaching Book. Jakarta: EGC.

Brand, E., Kothari, C., \& Stark, M.A. (2011). Factors related to breastfeeding discontinuation between hospital discharge and 2 weeks postpartum. J. Perinat. Educ. 20 (1), 36-44. doi: http://dx.doi.org/10.1891/1058-1243.20.1.36.

Buckles, K., \& Kolka, S. (2014). Prenatal investments, breastfeeding, and birth order. Soc. Sci. Med. 118, 66-70. doi: http://dx.doi.org/10.1016/j.socscimed.2014.07.0 55.

Byrne, B.M. (2013). Structural Equation Modeling with AMOS: Basic Concepts, Applications, and Programming. New York, NY: Routledge.

Chen, L.W., Low, Y.L., Fok, D., Han, W.M., Chong, Y.S., Gluckman, P., Godfrey, K., Kwek, K., Saw, S.M., Soh, S.E., Tan, K.H., Chong, M.F.F., \& van Dam, R.M. (2013). Dietary changes during pregnancy and the postpartum period in Singaporean Chinese, Malay, and Indian women: the GUSTO birth cohort study recommendations for prevention of excessive weight gain during pregnancy. Public Health Nutr. 17 (9), 1930-1938. doi: http://dx.doi.org/10.1017/S13689 $80 \quad 0130$ 01730.

Chin, A.C., Myers, L., \& Magnus, J.H. (2008). Race, education, and breastfeeding initiation in Louisiana, 2000-2004. J. Hum. Lact. 24 (2), 175185. doi: http://dx.doi.org/10.1177/0890334 408316074.
Chowdhury, P.P., Balluz, L., \& Strine, T.W. (2008). Health-related quality of life among minority populations in the United States, BRFSS 20012002. Ethn. Dis. 18 (4),483-487.

Cox, K.N., Giglia, R.C., \& Binns, C.W. (2015). The influence of infant feeding attitudes on breastfeeding duration: evidence from a cohort study in rural Western Australia. Int. Breastfeed. J. 10, 25. doi: http://dx.doi.org/10.1186/s130 0 6015-0 0483 .

de Oliveira, M.F., Parker, L., Ahn, H., Catunda, H.L.O., Bernardo, E.B.R., de Oliveira, M.F., Ribeiro, S.G., Calou, C.G.P., Antezana, F.J., Almeida, P.C., \& Castro, R.C.M.B. (2015). Maternal predictors for quality of life during the postpartum in Brazilian mothers. Health. 7 (03), 371. doi: http://dx.doi.org/10.4236/health.2015.730 42.

Department of Religious of Jember. (2011). The profile of health Jember District 2011. Jember: Published Bereau of Health Office Jember District.

Ministry of Health, Republic of Indonesia. (2009). National health system. Jakarta: Department Kesehatan.

Fok, D., Aris, I.M., Ho, J., Lim, S.B., Chua, M.C., Pang, W.W., Saw, S.M., Kwek, K., Godfrey, K.M., Kramer, M.S., \& Chong, Y.S. (2016). A comparison of practices during the confinement period among Chinese, Malay, and Indian Mothers in Singapore. Birth. 1-8. doi: http://dx.doi.org/10.1111/birt.12233.

Guelinckx, I., Devlieger, R., Bogaerts, A., Pauwels, S., \& Vansant, G. (2012). The effect of pre-pregnancy BMI on intention, initiation, and duration of breast-feeding. Public Health Nutr. 15 (5), 840848. doi: http://dx.doi.org/10.1017/S13689 80 011002667.

Hasugian, T.P. (2012). Knowledge, Attitude, and Behavior of Pregnant Women Against High Risk Pregnancy at RSUP H. Adam Malik Medan. Unpublished Thesis. Sumatera Utara: Fakultas Kedokteran Universitas Sumatera Utara.

Hauff, L.E., Leonard, S.A., \& Rasmussen, K.M. (2014). Associations of maternal obesity and psychosocial factors with breastfeeding intention, initiation, and duration. Am. J. Clin. Nutr. 99 (3), 524-534. http://dx.doi.org/10.3945/ajcn.113.071191.

Health Promotion Board. (2010). National Nutrition Survey 2010. Health Promotion Board, Singapore.

Ishak, S., Adzan, N., A.M., Quan, L.K., Shafie, M.H., Rani, N.A., \& Ramli, K.G. (2014). Knowledge and beliefs about breastfeeding are not determinants for successful breastfeeding. Breastfeed. Med. 9 (6), 308-312. doi: http://dx.doi.org/10.1089/bfm.2013.0124.

Kagawa-Singer, M., Padilla, G.V., \& Ashing-Giwa, K. (2010). Health-related quality of life and culture. Semin. Oncol. Nurs. 26 (1), 59-67. doi: http://dx.doi.org/10.1016/j.soncn.20 09.11.0 08. 
Kline, R.B. (2015). Principles and Practice of Structural Equation Modeling. New York, NY: Guilford Publications.

Kolu, P., Raitanen, J., \& Luoto, R. (2014). Physical activity and health-related quality of life during pregnancy: a secondary analysis of a clusterrandomised trial. Matern. Child Health J. 18 (9), 2098-2105. doi: http://dx.doi.org/10.10 07/s10995-014-1457-4.

Kost, K., \& Lindberg, L. (2015). Pregnancy intentions, maternal behaviors, and infant health: investigating relationships with new measures and propensity score analysis. Demography. 52 (1), 83-111. doi: http://dx.doi.org/10.10 07/s13524-014-03599.

Lau, Y., Htun, T.P., Lim, P.I., Ho-Limb, S.S.T., Chi, C., Tsai, C., Ong, K.W., \& Klainin-Yobas, P. (2016). Breastfeeding attitude, health-related quality of life, and maternal obesity among multi-ethnic pregnant women: a multi-group structural equation approach. International Journal of Nursing Studies. 67 (2017) 71-82.

Linares, A.M., Rayens, M.K., Gomez, M.L., Gokun, Y., \& Dignan, M.B. (2015). Intention to breastfeed as a predictor of initiation of exclusive breastfeeding in Hispanic women. J. Immigr. Minor. Health. 17, 1192-1198. doi: http://dx.doi.org/10.10 07/s10903-014-0 0 49-0.

Meedya, S., Fahy, K., \& Kable, A. (2010). Factors that positively in fluence breastfeeding duration to 6 months: a literature review. Women Birth. 23 (4), 135-145.

doi: http://dx.doi.org/10.1016/j.wombi.2010.02.0 02.

Ministry of Health. (2010). National Health Survey. Epidemiology and Disease Control Division. Ministry of Health, Singapore.

Mitra, A.K., Khoury, A.J., Hinton, A.W., \& Carothers, C. (2004). Predictors of breastfeeding intention among low-income women. Matern. Child Health $\begin{array}{llll}\text { J. } & 8 & \text { (2), 65-69. doi: }\end{array}$ http://dx.doi.org/10.1023/B:MACI.0 00000 025728.54271.27.

Montoya Arizabaleta, A.V., Orozco Buitrago, L., Aguilar de Plata, A.C., Mosquer Escudero, M., \& Ramirez-Velez, R. (2010). Aerobic exercise during pregnancy improves health-related quality of life: a randomised trial. J. Physiother. 56 (4), 253-258. doi: $\quad$ http://dx.doi.org/10.1016/S18369553(10)70 0 08-4.

Neelakantan, N., Whitton, C., Seah, S., Koh, H., Rebello, S.A., Lim, J.Y., Chen, S., Chan, M.F., Chew, L., \& van Dam, R.M. (2016). Development of a semi-quantitative food frequency questionnaire to assess the dietary intake of a multi-ethnic urban Asian population. Nutrients. 8 (9) doi: http://dx.doi.org/10.3390/nu8090528.

Nisar, Y.B., Aurangzeb, B., Dibley, M.J., \& Alam, A. (2016). Qualitative exploration of facilitating factors and barriers to use of antenatal care services by pregnant women in urban and rural settings in Pakistan. BMC Pregnancy Childbirth.
16 (42), 1-9. doi: http://dx.doi.org/10.1186/s12884-016-0829-8.

Nouer, S.S., Ware, J.L., Baldwin, K.M., Hare, \& M.E. (2015). Changes in breastfeeding attitudes in a metropolitan community in Tennessee. J. Hum Lact. $\quad 31 \quad$ (3), 519-529. doi: http://dx.doi.org/10.1177/0890334 4155786 48.

Olmedo-Alguacil, M.M., Ramirez-Rodrigo, J., Villaverde-Gutierrez, C., Sanchez Caravaca, M.A., Aguilar Ferrandiz, E., \& Ruiz-Villaverde, A. (2015). Health related quality of life, gender, and culture of older people users of health services in the multicultural landscape of the city of Ceuta (Spain): a cross-sectional study. J. Transcult. Nurs. 1-8. doi: http://dx.doi.org/10.1177/1043 659615597042.

Padmapriya, N., Shen, L., Soh, S.E., Shen, Z., Kwek, K., Godfrey, K.M., Gluckman, P.D., Chong, Y.S., Saw, S.M., \& Müller-Riemenschneider, F. (2015). Physical activity and sedentary behavior patterns before and during pregnancy in a multi-ethnic sample of Asian women in Singapore. Matern. Child Health J. 19 (11), 2523-2535. doi: http://dx.doi.org/10.10 07/s10995-015-1773-3.

Persad, M.D., \& Mensinger, J.L. (2008). Maternal breastfeeding attitudes: association with breastfeeding intent and socio-demographics among urban primiparas. J. Commun. Health. 33 (2), 53- 60. doi: http://dx.doi.org/10.10 07/s1090 0-0 07-90 8-2.

Radzyminski, S., \& Callister, L.C. (2016). Mother's beliefs, attitudes, and decision making related to infant feeding choices. J. Perinat. Educ. 25 (1), 1828. doi: http://dx.doi.org/10.1891/10581243.25.1.18.

Roll, C.L., \& Cheater, F. (2016). Expectant parents' views of factors influencing infant feeding decisions in the antenatal period: a systematic review. Int. J. Nurs. Stud. 60, 145-155. doi: http://dx.doi.org/10.1016/j.ijnurstu.2016.0 4.011.

Saraswati, E. (1998). Resiko Ibu Hamil Kurang Energi Kronis (KEK) dan Anemia untuk melahirkan Bayi dengan Berat Badan Lahir Rendah (BBLR). Jakarta: Penerbit Jawa Barat.

Tsai, S.Y., Lee, P.L., Lin, J.W., \& Lee, C.N. (2016). Cross-sectional and longitudinal associations between sleep and health-related quality of life in pregnant women: a prospective observational study. Int. J. Nurs. Stud. 56, 45-53. doi: http://dx.doi.org/10.1016/j.ijnurstu.2016.01.0 01.

Turcksin, R., Bel, S., Galjaard, S., \& Devlieger, R. (2014). Maternal obesity and breastfeeding intention, initiation, intensity and duration: a systematic review. Matern. Child Nutr. 10 (2), 166-183. doi: http://dx.doi.org/10.1111/j.17408709.2012.004 39.x. 
Victora, C.G., Bahl, R., Barros, A.J., Franca, G.V., Horton, S., Krasevec, J., Murch, S., Sankar, M.J., Walker, N., \& Rollins, N.C. (2016). Lancet Breastfeeding Series, G. 2016. Breastfeeding in the 21st century: epidemiology, mechanisms, and life-long effect. Lancet. 387 (10017), 475-490. doi: http://dx.doi.org/10.1016/s01406736(15)01024-7.

Wang, W., Lau, Y., Chow, A., \& Chan, K.S. (2014). Breast-feeding intention, initiation, and duration among Hong Kong Chinese women: a prospective longitudinal study. Midwifery. 30 (6), 678-687. doi:http://dx.doi.org/10.1016/j.midw.2013.07.0 15.

Ware, J.E., Kolinski, M., \& Keller, S.D. (1995). How to Score the SF-12 Physical and Mental Health Summaries: a User's Manual. The Health Institute, New England Medical Centre, Boston, MA.
World Health Organization. (2016). Obesity and Overweight. World Health Organization. http://www.who.int/mediacentre/factsheets/fs3 11/en/. (Accessed : June 2, 2018)

Zahran, H.S., Kobau, R., Moriarty, D.G., Zack, M.M., Holt, J., \& Donehoo, R. (2005). Health-related quality of life surveillance-United States, 19932002. MMWR Surveill. Summ. 54 (4), 1-35.

Zhou, Q., Younger, K.M., \& Kearney, J.M. (2010). An exploration of the knowledge and attitudes towards breastfeeding among a sample of Chinese mothers in Ireland. BMC Public Health. 10 (722), $1-11$. doi: http://dx.doi.org/10.1186/1471-2458-10-722.

Zubaran, C., \& Foresti, K. (2011). The correlation between breastfeeding and maternal quality in Southern Brazil. Breastfeed. Med. 6 (1), 25-30. doi: http://dx.doi.org/10.1089/bfm.2010.0 017. 